\title{
NYAMBEI DALAM BIMBANG PERNIKAHAN PADA ETNIK REJANG
}

\author{
'Riqqah Dhiya Ramadhanty; ${ }^{2}$ Sarwit Sarwono; ${ }^{3}$ Agus Joko Purwadi
}

\section{Program Studi Pendidikan Bahasa Indonesia Jurusan Pendidikan Bahasa dan Seni FKIP Universitas Bengkulu}

\section{Abstrak}

\section{Korespondensi: riqqahh21@gmail.com}

Tujuan penelitian untuk memahami dan menjelaskan nyambei dalam bimbang pernikahan etnik Rejang. Metode penelitian yang digunakan adalah metode penelitian kualitatif etnografi. Data pada penelitian ini diperoleh melalui studi lapangan yang mencakup teks sambei dan rekaman audio maupun visual. Sumber data dari penelitian ini adalah kegiatan observasi, dokumentasi, wawancara terhadap informan yang dinilai memiliki pengetahuan dan pemahaman terhadap nyambei. Lokasi penelitian dilakukan di desa Lubuk Kembang kecamatan Curup Utara kabupaten Rejang Lebong. Teknik analisis data dilakukan dengan tahapan penafsiran, penjelasan, dan deskripsi. Bimbang pernikahan merupakan pesta akan perayaan pernikahan dalam masyarakat Rejang, mereka biasa merayakannya dengan menyelenggarakan kejai. Umumnya kejai dilaksanakan dalam jangka waktu tujuh hari. Inti acara kejai adalah menari kejai yang ditarikan oleh anok sangei. Saat menari para anok sangei akan berhenti tiba-tiba untuk melantunkan sambei. Lirik sambei menggambarkan kehidupan masyarakat Rejang salah satunya adalah hierarki sosial, adab kesantunan, penunjuk kekuasaan, nasihat, dan ungkapan pelipur lara. Setelah melalukan analisis, hasil dari penelitian ini adalah untuk memaknai sambei diperlukan pemahaman terhadap latar belakang etnografi masyarakat pemilik sambei agar menemukan pemaknaan yang tepat. Selain itu sambei juga berfungsi pendidikan, pengesahan strata sosial, proyeksi keinginan, dan penekan berlakunya nilai dalam masyarakat.

Kata Kunci: rejang, sambei, kejai, bimbang, etnografi

\section{Abstract}

The aim of the study was to understand and explain nyambei in bimbang marriage of Rejang ethnic. The research method used is an ethnographic qualitative research method. The data in this study were obtained through field work that included sambei texts, audio and visual recordings. Sources of data from this study are observation, documentation, interviews with informants who are considered to have knowledge and understanding of nyambei. The location of the study was conducted in Lubuk Kembang village, Curup Utara district, Rejang Lebong district. Data analysis techniques are carried out with stages of interpretation, explanation, and description. Bimbang marriage is a party for wedding celebrations in the Rejang community, they usually celebrate by holding a ceremony. Generally, kejai is carried out within a period of seven days. The core of the kejai ceremony is the dance which is danced by anok sangei. When dancing the anok sangei will stop suddenly to sing sambei. Sambei's lyrics describe the life of the Rejang people, one of which is social hierarchy, courtesy, authority, advice and expressions of solace. After carrying out the analysis, the results of this study were to interpret sambei as an understanding of 
the ethnographic background of the sambei owners in order to find the right meaning. Apart from that sambei also functions education, ratification of social strata, projections of desire, and suppressing the validity of values in society.

Keywords: rejang, sambei, kejai, bimbang, ethnographic

\section{PENDAHULUAN}

Setiap kebudayaan memiliki unsur-unsur universal yang saling berinteraksi dan melahirkan ekspresi budaya otentik yang berbeda satu dan lainnya. Perbedaan ini tidak menghilangkan unsur-unsur universal yang menjadi dasar dalam setiap kehidupan. Koentjaraningrat (2015:2) menjelaskan tujuh unsur universal yang membentuk masingmasing sistem. Ialah sistem religi, sistem organisasi masyarakat, sistem pengetahuan, sistem bahasa, sistem kesenian, sistem mata pencaharian, dan sistem teknologi. Tujuh unsur universal kebudayaan ini dapat ditemukan pada seluruh kebudayaan manusia yang ada di dunia, tidak terkecuali dengan kebudayaan Rejang.

Sejak tahun 1783, William Marsden telah mengamati kelompok etnik Rejang dan menuangkan deskripsinya ke dalam buku History of Sumatera. Dalam bukunya, Marsden menceritakan Rejang sebagai kebudayaan yang memiliki klaim keaslian dibandingkan kelompok etnik lainnya yang terdapat di Sumatera kendati letaknya di posisi sentral sehingga mendapat pengaruh dari orang-orang Melayu dari selatan dan pengaruh orangorang Jawa dari Utara. Rejang memiliki luas kekuasaan terbesar di provinsi Bengkulu dibanding lima kelompok etnik asli Bengkulu lainnya yaitu Serawai, Pekal, Basemah, Bintuhan, Lembak, dan Enggano. Hingga saat ini orang-orang Rejang mendiami wilayah kabupaten Bengkulu Utara, Lebong, Rejang Lebong, Kepahiang, dan Bengkulu Tengah.

Sebagai sebuah kelompok etnik yang besar, orang Rejang memiliki unsur universal kebudayaannya sendiri. Unsur-unsur universal tersebut hingga saat ini dapat dilihat dalam wujud perayaan besar yang disebut dalam istilah bimbang. Bimbang merupakan istilah yang digunakan orang Rejang untuk menyebut perhelatan acara untuk merayakan momen penting dalam kehidupan, sering kali mereka juga menyebutnya dalam istilah kejai. Istilah bimbang lebih luas penggunaannya dari istilah kejai, orang-orang Basemah, Bintuhan, dan Serawai juga menggunakan istilah tersebut. Bimbang digunakan oleh orang-orang Melayu Bengkulu yang datang dari pesisir sedangkan kejai hanya digunakan oleh orang Rejang saja (Siddik, 1980:268). Dewasa ini, orang-orang Rejang juga sering menggunakan istilah bimbang.

Orang-orang Rejang mengadakan kejai untuk merayakan hal-hal tertentu, di antaranya adalah penyambutan raja, perayaan panen, pengangkatan pemimpin, menindik bayi, khitanan, khatam Al-Quran, pernikahan, dan hal lainnya tergantung dengan keinginan juga niat dari keluarga penyelenggara. Hingga saat ini kejai rutin dilaksanakan setiap tahunnya dalam perayaan HUT kabupaten Rejang Lebong, selain itu masyarakat Rejang sering menyelenggarakan kejai untuk merayakan pesta pernikahan. Oleh karena itu, penelitian ini akan fokus membahas kejai pernikahan.

Kejai pernikahan terdiri dari serangkaian ritual adat yang diadakan selama beberapa hari, umumnya kejai berlangsung selama tujuh hari, akan tetapi ada juga yang mengadakan selama tiga hari hingga empat puluh hari, tergantung keinginan tuan rumah penyelenggara. Dalam rangkaian ritual tersebut, yang menjadi inti acara adalah tari kejai. Tarian ini merupakan ritual sakral, orang-orang Rejang percaya bahwa ketika sedang menari kejai para dewa turun dan ikut menari. Oleh karena itu, tidak sembarang orang 
diperbolehkan menari kejai. Dalam ritualnya yang sakral tarian ini hanya boleh ditarikan oleh perempuan dan laki-laki muda yang masih perawan dan dalam keadaan suci (tidak sedang haid), mereka dipanggil dengan sebutan anok sangei.

Tarian kejai ditarikan secara berpasangan dalam jumlah ganjil, misalnya lima pasang, tujuh pasang, hingga sembilan pasang. Laki-laki dan perempuan yang menjadi anok sangei tidak boleh berasal dari marga ${ }^{1}$ yang sama. Hal ini diatur oleh jakso yang bertanggung jawab terhadap pelaksanaan kejai. Karena peraturan tersebut, tari kejai dijadikan sebagai ajang perjumpaan antara muda-mudi yang berasal dari marga yang berbeda. Sering kali mereka mencari calon pendamping hidup ketika sedang menari kejai. Akan tetapi peraturan menari kejai tidak membolehkan anok sangei untuk saling berinteraksi secara langsung. Oleh karena itu, untuk mengekspresikan diri anok sangei dapat menyampaikan perasaannya dalam nyambei.

Ritual nyambei dilakukan ditengah-tengah prosesi menari kejai. Ketika anok sangei tengah menari, jakso akan memerintahkan pemain musik untuk berhenti sebagai pertanda akan dimulainya nyambei, pemberhentian mendadak ini disebut dengan ngandak. Nyambei berasal dari kata sambei dengan penambahan imbuhan ny- di depan kata yang berarti kegiatan atau suatu proses. Sehingga nyambei berarti kegiatan melantunkan sambei.

Sambei merupakan teks nyanyian yang berisikan syair maupun pantun rakyat Rejang. Sambei lahir dari proses yang spontan dan ekspresif tergantung dari konteks dan situasi sambei tersebut dilantunkan. Dewasa ini, orang Rejang melantunkan sambei yang telah diwariskan secara turun-temurun sehingga kata-kata dalam sambei merupakan bahasa Rejang yang kuno dan menggunakan metafora-metafora yang hanya di pahami oleh orang-orang Rejang dahulu.

Selain sebagai bentuk ekspresi diri anok sangei, nyambei juga mencerminkan ekspresi kebudayaan Rejang secara luas. Makna yang terkandung di dalam sambei merupakan makna yang lahir dari gagasan dan ide kebudayaan Rejang secara keseluruhan. Sayangnya, dewasa ini orang-orang Rejang tidak lagi melakukan usaha untuk memahami makna tersirat tersebut. teks sambei hanya sekadar dilantunkan tanpa interpretasi apapun, terlebih makna yang terkandung merupakan nilai-nilai otentik etnik Rejang sendiri yang terancam hilang.

Apabila dikelompokkan ke dalam jenis folklor, maka nyambei termasuk ke dalam bentuk folklor setengah lisan. Prosesi nyambei melibatkan tidak hanya teks sambei, tetapi juga terdapat unsur tarian, ritual, benda-benda sakral, dan beberapa tokoh adat yang wajib dihadirkan. Hal ini sejalan dengan yang dijelaskan oleh Danandjaja mengenai ciri-ciri folklor setengah lisan (1997:3-4). Dari unsur-unsur yang membangunnya, nyambei dalam kejai dapat disebut sebagai sebuah pertunjukan kebudayaan. Ketika anok sangei melantunkan sambei, pertunjukan tersebut dihadiri oleh seluruh warga desa dan tamutamu undangan yang datang dari seluruh marga Rejang. Pertunjukan nyambei bernilai sakral dalam masyarakat Rejang, tidak sembarang orang dapat berperan serta di dalam pertunjukan tersebut. Orang-orang Rejang percaya bahwa tarian kejai dan sambei merupakan persembahan kepada dewa-dewa, hal ini sejalan dengan konteks dan fungsi pertunjukan masyarakat etnik yang dijelaskan oleh Sedyawati (1981:48-67).

Selain fungsinya sebagai sebuah pertunjukan, nyambei memiliki makna yang kompleks bagi masyarakat Rejang. Di dalam nyambei ditemukan pranata-pranata kebudayaan yang saling berkaitan (Koentjaraningrat, 1974:18). Secara umum sambei digunakan sebagai media ekspresif yang bertujuan menyatakan perasaan terhadap lawan 
pesambei. Tujuan dari penggunaan sambei ini tidak lain adalah untuk mengadakan hubungan kekerabatan berupa pernikahan. Oleh karena itu, sambei sering kali berisi puji-pujian akan kecantikan, kelincahan, kegagahan, maupun ketangkasan seseorang.

Tidak hanya bertujuan untuk mengadakan hubungan kekerabatan, sambei juga digunakan untuk tujuan pranata kebudayaan lainnya. sambei yang lahir dari proses yang spontan dan ekspresif menjadikan sambei sebagai karya yang kontekstual dan situasional. Makna sambei tergantung dari tujuan sambei tersebut dilantunkan, orang-orang Rejang juga melantunkan sambei saat menyambut raja, peringatan kematian, dan momentum lainnya apabila sambei dibutuhkan, keberadaannya tidak terikat pada tatanan ritual.

Nyambei sebagai salah satu bentuk folklor memiliki makna bagi masyarakatnya. Makna tersebut terdapat pada metafora-metafora yang dikemas dalam bahasa Rejang kuno dan istilah-istilah dalam bahasa yang lain. Untuk memahaminya diperlukan pengamatan dan pemahaman terhadap etnografi etnik Rejang.

Nyambei tidak hanya kegiatan melantunkan teks, dalam pelaksanaannya nyambei merupakan kesatuan pertunjukan kebudayaan yang melibatkan banyak unsur. Untuk mendapatkan pemaknaan yang tepat, dibutuhkan pengamatan etnografi agar dapat menemukan nilai-nilai tersirat tersebut. Pengetahuan akan etnografi etnik Rejang atau secara khusus terhadap ritual kejai akan memberikan perspektif dan interpretasi yang paling mendekati pemaknaan yang tepat. Tahapan dalam pengamatan etnografi akan dilakukan menggunakan langkah-langkah Spradley. Analisis nyambei menggunakan pendekatan sosiopragmatik yaitu mengkaitkan antara situasi etnografi masyarakat Rejang dengan teks sambei yang akan diinterpretasikan.

Dari hasil observasi awal peneliti terhadap sambei, posisi, serta keterkaitannya dalam rangkaian ritual besar kejai. Peneliti tertarik melakukan penelitian lebih lanjut mengenai nyambei dengan judul penelitian Nyambei dalam Bimbang Pernikahan pada Etnik Rejang. Rumusan masalah dari penelitian ini adalah memaknai nyambei dalam bimbang pernikahan etnik Rejang. Penelitian ini bertujuan untuk memahami dan menjelaskan secara mendalam mengenai nyambei dalam bimbang pernikahan etnik Rejang. Peneliti berharap penelitian ini dapat bermanfaat bagi masyarakat luas guna memperkaya literatur mengenai etnik Rejang.

\section{METODE}

Metode yang digunakan dalam penelitian ini adalah metode kualitatif etnografi. Penelitian etnografi merupakan penelitian kualitatif yang meneliti suatu kelompok budaya yang terdapat dalam masyarakat secara ilmiah yang bertujuan untuk mendeskripsikan, menganalisis, dan menafsirkan pola budaya suatu kelompok dalam hal perilaku, kepercayaan, bahasa dan pandangan yang dianut bersama.

Penelitian mengenai nyambei ini menggunakan pendekatan kualitatif agar dapat mengupas tentang makna dan fungsinya secara mendalam. Hasil dari penelitian ini adalah berupa deskripsi mengenai masyarakat yang diamati, sehingga dalam proses penelitian menggunakan pendekatan kualitatif ini peneliti harus terjun langsung ke masyarakat Rejang yang merupakan pemilik tradisi nyambei.

Ada beberapa data yang digunakan dalam penelitian ini, antara lain rekaman rangkaian gerakan tarian kejai, rekaman nyambei, rekaman variasi gerakan tarian kejai, rekaman variasi nyambei, dan teks sambei. Data ini peneliti peroleh dari informan yang berasal dari BMA Kabupaten Rejang Lebong antara lain Bapak Baksir, Bapak Nasrul 
Dahuri, dan Bapak Ahmad Faizir. Selain dari pihak BMA peneliti juga mewawancarai pelaku kesenian adat Rejang yaitu Bapak Abdul Muis, Bapak R. Sumantri, dan Ibu Nir Hasanah. Peneliti juga mewawancarai masyarakat biasa yang menjadi saksi mata pertunjukan kejai yaitu Ibu Nuraini. Teknik yang digunakan dalam pemilihan informan adalah purposive sampling yaitu dengan memilih narasumber atau informan yang dinilai paling berkompeten dan memahami topik penelitian. Lokasi penelitian tersebar di Kabupaten Rejang Lebong akan tetapi terfokus di Desa Lubuk Kembang Kecamatan Curup Utara.

Subjek penelitian ini adalah informan yang merupakan pelaku kesenian adat Rejang dan masyarakat awam etnik Rejang. Peneliti membutuhkan kedua jenis informan tersebut untuk memperoleh persepsi yang luas dari perspektif pelaku adat dan masyarakat biasa. Teknik penelitian yang digunakan adalah dengan teknik observasi, wawancara, catatan langsung etnografi, dan dokumentasi. Sedangkan langkah teknik analisis data yang digunakan adalah dengan (1) mencari dan mengumpulkan data, (2) mentranskripkan data, (3) menerjemahkan data, (4) mengolah data, dan (5) menarik kesimpulan.

\section{HASIL DAN PEMBAHASAN}

\section{Hasil}

Berdasarkan hasil pengamatan etnografi dan analisis teks sambei dengan pendekatan sosiopragmatik, ditemukan hasil sebagai berikut: Dalam bahasa Rejang, kejai berarti perayaan yang ramai atau keramaian, hal ini dikarenakan setiap diadakannya kejai maka seluruh orang dari berbagai etnik marga akan datang dan memenuhi tempat tersebut. Kejai biasanya dilaksanakan dalam jangka waktu yang lama biasanya tujuh hari, tetapi ada pula yang menyelenggarakannya hingga empat puluh hari. Tuan rumah yang menyelenggarakan kejai harus menyediakan makanan bagi seluruh tamu undangan yang datang dari seluruh marga Rejang selama kejai diselenggarakan. Oleh karena itu, menyelenggarakan kejai membutuhkan biaya yang sangat besar sehingga di masa ini sudah sangat jarang orang yang sanggup menyelenggarakan kejai.

Kejai diselenggarakan pada balai panjang, yaitu bangunan non permanen yang terbuat dari papan dengan luas minimal 6x8 meter persegi. Bangunan ini disusun sedemikian rupa agar terdapat bilik-bilik yang telah ditentukan sebagai posisi para penari, pemain musik, tokoh adat, pemimpin adat, tamu undangan, dan penonton. Di tengahtengah balai terdapat penei, yaitu simbol kemakmuran dan kesejahteraan bagi masyarakat Rejang yang terbuat dari berbagai macam alat dan bahan. Dalam perayaan kejai pernikahan ada beberapa ritual yang harus dilaksanakan, akan tetapi puncak dari perayaan kejai adalah dengan menari kejai yang ditarikan oleh muda-mudi desa atau biasa disebut anok sangei, di dalam tari kejai terdapat pula suatu prosesi penting yaitu nyambei atau masyarakat sering menyebutnya dengan istilah ngandak, nyambei dan ngandak merupakan dua aspek yang merupakan satu-kesatuan, apabila dalam tarian kejai dilakukan ngandake maka itu merupakan saatnya nyambei, akan tetapi nyambei dapat dilakukan pada saat selain ngandak. Misalnya, nyambei yang dilakukan pada saat sekadar berkumpul bersama seluruh warga desa pada malam hari, untuk bercerita dan menjadi hiburan, selain itu ngandake hanya dilaksanakan pada saat kejai. kejai merupakan sebuah perhelatan besar yang tidak terpisahkan dengan tari kejai, begitu pula hubungannya tari kejai dengan nyambei, setiap menari kejai pasti diawali dengan sambei kemudian dilanjutkan di tengah-tengah menari. Sedangkan sebaliknya nyambei dapat dilaksanakan di luar pelaksanaan tari kejai. 
Orang-orang biasa melantunkan nyambei tidak hanya pada saat tari kejai, tetapi juga dilantunkan pada saat-saat penting lainnya seperti kematian, atau pada saat berkumpul-kumpul di malam hari saja. Sambei yang dilantukan pada saat menari kejai dikenal dengan istilah sambei andak, sedangkan sambei yang dilantunkan di luar menari kejai disebut sambei saja. Lirik syair dan pantun sambei tidak memiliki pakem khusus, hal ini tergantung kreatifitas dan kemahiran pesambei dalam merangkai syair sambei.

Berdasarkan wawancara dan observasi, peneliti berhasil menemukan delapan sambei yaitu Sambei Temimo Rajo yang peneliti dapatkan dari seorang mantan pesambei gadis bernama Nir Hasanah (Selanjutnya sambei ini disebut dengan nama S-NH), Sambei Malem yang peneliti dapatkan dari buku yang ditulis oleh Kadirman (2004:117), Sambei Ngesiyen yang juga peneliti dapatkan dari buku yang ditulis oleh Kadirman (Selanjutnya Sambei Malem disebut dengan nama S-KD 1 dan Sambei Ngesiyen disebut dengan nama S-KD 2).

Kelima sambei lainnya tidak memiliki nama khusus karena para pesambei menyebutnya dengan nama yang sama yaitu sambei andak. Oleh karena itu peneliti menyebutnya dengan nama informan yang memiliki sambei tersebut. SA-AM merupakan sambei andak yang peneliti dapatkan dari Abdul Muis, SA-NH merupakan sambei andakyang peneliti dapatkan dari Nir Hasanah, SA-BS merupakan sambei andak yang peneliti dapatkan dari Baksir Z, SA-RS merupakan sambei andak yang peneliti dapatkan dari R. Sumantri, dan yang terakhir SA-ND merupakan sambei andak yang peneliti dapatkan dari Nasrul Dahuri.

Pada saat nyambei, orang yang melantunkan sambei biasanya menutup wajahnya dengan sebuah kipas atau kain atau kulit kayu sambil diiringi dengan suara sedem atau suling bambu. Tidak sembarang orang bisa melantunkan sambei, karena untuk nyambei memerlukan keterampilan dan bakat dalam olah suara. Orang yang bisa menyambei biasanya adalah orang yang memiliki suara yang indah. penggunaan penutup wajah seperti kipas atau kain pada zaman dahulu dipercaya sebagai filter suara agar menjadi lebih lantang dan jernih.

Setelah dilakukan analisis, ditemukan aspek-aspek kehidupan masyarakat tradisional yang berkaitan dengan fungsi sambei dalam masyarakat. Di antaranya yang ditemukan peneliti bahwa di dalam sambei terdapat kata, frasa, dan kalimat yang menunjukkan tanda-tanda keberadaan hierarki sosial, adab kesantunan, penunjuk kekuasaan, aturan-aturan adat, nasihat, dan ungkapan pelipur lara.Pada S-NH yang memiliki judul sambei temimo rajo merupakan salah satu sambei yang menunjukkan hierarki sosial di dalam masyarakat Rejang. Kata temimo rajo yang berarti 'terima raja' bermakna bahwa sambei ini ditujukan pada saatpenerimaan atau penyambutan kedatangan raja. Makna yang terdapat di dalamnya menggambarkan rasa hormat dan penghambaan terhadap superioritas raja, seperti yang tergambar dalam bait berikut.

\section{Sembah ku angkat kareno rajo}

Riwe ku junjung karno perwatin Setabik..

Kata sembah dan riwe yang berarti sikap hormat menunjukkan tingkatan sosial seorang raja yang berada di atas rakyatnya dan merupakan seorang yang harus di hormati. Sembah bukan bermakna religius, tetapi berarti penghormatan yang sangat dalam karena kepercayaan akan keagungan dan kekuasaan raja. Rajo merupakan sebutan atau gelar bagi kepala petulai sedangkan perwatin atau proatin merupakan sebutan bagi kepala dusun. Dalam hierarki sosial masyarakat Rejang, rajo menduduki tingkatan tertinggi karena memimpin 


\section{Riqqah Dhiya Ramadhanty; Sarwit Sarwono; Agus Joko Purwadi}

sebuah kerajaan atau petulai. Kemudian di bawah tingkatan rajo terdapat pasirah yang memimpin marga lalu satuan masyarakat yang lebih kecil di bawahnya di pimpin oleh proatin atau ginde. Selain adanya hierarki sosial, penyebutan nama tokoh penting dalam sambei juga menunjukkan adanya tanda penunjuk kekuasaan terhadap tokoh-tokoh tertentu. seperti yang terdapat pada SA-BS yang menyebutkan nama Ki Rio Setanggai Panjang dan Monok Micor dalam lirik berikut.

Pata tanggai kerio si tanggai panjang Monok micor tenga gelanggang

Kerio si tanggai panjang adalah penyebutan nama Ki Rio Setanggai Panjang. dalam silsilah keluarga kerajaan Petulai Jurukalang ${ }^{9}$ Ki Rio Setanggai Panjang merupakan saudara dari Rajo Rio Muun yang mengganti ayahnya memimpin Petulai Jurukalang, kemudian Ki Rio Setanggai Panjang menggantikan saudaranya memimpin Petulai Jurukalang. Ki Rio Setanggai Panjang lahir dalam kondisi memiliki kuku-kuku yang sangat panjang. Oleh Karena itu, beliau diberi nama setanggai yang berarti kuku. Sedangkan nama Monok Micor merupakan saudara dari Rajo Anak Dalam yang memimpin Kerajaan Sungai Serut, Monok Micor kemudian mendirikan kelompok etnik Lembak.

Dalam SA-ND juga terdapat penyebutan nama tokoh penguasa dalam sambei, terdapat pada lirik berikut.

\section{Pata tanggai, pengiran bingin}

Tidak diketahui secara pasti siapa Pengiran Bingin tersebut, akan tetapi kata pengiran merupakan gelar pangeran dalam tradisi melayu sehingga dapat dipastikan bahwa orang yang disebutkan menggunakan gelar pengiran bukanlah orang biasa. Penyebutan nama tokoh-tokoh penting menguasa menunjukkan adanya pengaruh superioritas kekuasaan terhadap masyarakat Rejang sehingga nama tokoh penguasa tersebut digunakan untuk menggambarkan kekuatan, kepercayaan diri, dan kewibawaan dalam sambei.

Dalam SA-AM dan SA-BS ditemukan adab kesantunan dalam masyarakat Rejang yang terkandung dalam lirik berikut.

SA-AM

Kami mencadang siri dan pinang

SA-BS

Pata melukon la gedung iben

Iben yang disebutkan di atas merupakan wadah sirih yang biasa digunakan pada saat menari kejai maupun yang terletak di bawah penei sedangkan gedung berasal dari kata godong yang berarti daun. Dalam bahasa jawa godhong juga berarti daun, sehingga godong iben dapat diartikan sebagai wadah daun nyirih. Begitu juga kata mencadang siri dan pinang bermakna menyuguhkan sirih dan pinang.

Dalam kebudayaan nusantara, menyuguhkan sirih merupakan tanda penghormatan dan memuliakan tamu. Reid (2014:51) mengatakan bahwa sajian sirih merupakan hakikat sopan-santun dan keramah-tamahan, sajian sirih selalu dimunculkan pada ritus-ritus penting dalam kehidupan seperti pernikahan, kematian, kelahiran, dan penyembuhan. Sirih disajikan dengan dua bahan utama lainnya yaitu buah pinang dan kapur, ketiga bahan utama ini disajikan di dalam wadah yang disebut dengan iben. Kegiatan ini sangat disukai sehingga kedudukan sirih pada zaman itu mengalahkan posisi juadah untuk menemani keramahtamahan sehari-hari. Apabila pada saat ini menjamu tamu dengan teh atau kopi, 
maka pada abad 17 sajian utamanya adalah sirih dan pinang (Reid, 2014).

Pada SA-AM ditemukan juga nasihat yang dibalut dalam metafora dongeng burung Srigunting dan Elang. Berikut adalah lirik yang menunjukkan hal tersebut.

Sawi biring terbang ruput Terbang segale raje burung

Kata sawi biring merupakan salah satu jenis burung yang terdapat di Sumatera yaitu burung sawi atau masyarakat Melayu biasa menyebutnya dengan nama burung Srigunting. Burung Srigunting memiliki tubuh yang kecil dengan ekor panjang terbelah dua mirip dengan bentuk gunting, jenis burung ini memiliki kicauan yang indah dan dapat meniru suara serta tingkah laku jenis burung lainnya. kata terbang ruput bermakna terbang rendah yang mendekati rumput.

Kata terbang segale dalam bahasa Lembak berarti terbang segala, kemudian raje burung berarti raja burung yang selama ini seringkali dikaitkan dengan burung Elang. Di alam bebas, Elang merupakan salah satu raptor ${ }^{10}$ yang menduduki kasta tertinggi dalam trofik ekologi. Karakter Elang yang buas, tubuh yang besar, cakar tajam, dan paruh yang kuat membuat Elang hampir bebas gangguan dari jenis burung lainnya. Akan tetapi, Srigunting adalah jenis burung yang berani melawan superioritas Elang meskipun bertubuh lebih kecil. Mereka mampu 'mengganggu' Elang sebagai bentuk sikap antipredator dan pertahanan teritori dengan cara meniru suara predator lain yang telah dikuasainya, tindakannya ini dapat membuat Elang terbang menjauh.

Perilaku alamiah burung Srigunting dan Elang ini juga tergambar dalam dongeng burung Srigunting dan Elang Si Raja Udara, dalam dongeng tersebut dikisahkan bahwa burung Srigunting mengalahkan Elang yang pongah dan sombong dalam adu kekuatan terbang. Elang kalah dan mati sehingga teman-teman elangnya yang sombong terbang pergi meninggalkannya jatuh sendiri. Dua baris sambei yang berbunyi sawi biring terbang ruput, terbang segale raje burung dapat diartikan bahwa burung sawi kecil yang biasa terbang rendah mampu mengusir raja burung hingga terbang menjauh.

Nasihat yang dapat disimpulkan adalah bahwa untuk melawan kemungkaran tidak diperlukan kekuatan akan tetapi cukup dengan kecerdikan dan kecerdasan seperti yang dimiliki oleh Burung Srigunting selain itu dongeng ini juga bermakna bahwa kepongahan dan kesombongan tidak akan berakhir baik.

Hampir dalam setiap sambei selalu diakhiri dengan bait yang berisi tentang prosesi adat yang menunjukkan adanya penggunaan-penggunaan barang-barang tertentu sebagai aturan adat. seperti yang ditemukan pada bait terakhir S-TR, bait ketiga SA-BS, bait keempat SA-RS, bait terakhir SA-AM, dan bait ketiga SA-NH. Bait tersebut tidak selalu dimunculkan dalam baris yang lengkap, sehingga peneliti hanya akan membahas bait yang terdapat pada SA-RS sebagai berikut.

\section{Andak tepuk kilauan surak. \\ Andak bedak kilauan pupur \\ Andak minyak kilauan buri \\ Andak sambei kilauan gandoi \\ Andak bujang kilauan gadis}

Kata andak pada bait ini dapat diartikan sebagai ungkapan, sedangkan kata kilauan yang sebenarnya adalah kelawan berarti lawan atau berbalas. Ada lima baris kalimat yang seluruhnya memiliki pola yang sama, perbedaan antar kalimat terletak pada dua hal atau dua benda yang dilawankan satu sama lain. Yaitu tepuk dengan surak, bedak dengan pupur, 


\section{Riqqah Dhiya Ramadhanty; Sarwit Sarwono; Agus Joko Purwadi}

minyak dengan buri, sambei dengan gandoi, dan bujang dengan gadis.

Menurut adat Rejang, kata yang di pasangkan dalam bait tersebut memanglah suatu hal yang berpasangan dan tidak dapat dipisahkan, seperti ketika bertepuk maka akan diiringi dengan sorakan. Kemudian benda-beda seperti bedak, pupur, minyak, dan buri merupakan benda-benda yang wajib digunakan ketika kejai. Bedak dan pupur digunakan untuk besink yaitu berdandan bagi gadis Rejang, sedangkan minyak dan buri merupakan ramuan sedingin setawar yang digunakan untuk melangir alat musik, ruangan, penari, dan lainnya. sambei dan gandoi juga merupakan hal yang tidak dapat dipisahkan, gandoi merupakan waktu dimana sambei dilantunkan yaitu selama semalam suntuk. Sedangkan bujang haruslah berpasangan dengan gadis.

Penunjukan pasangan-pasangan benda tersebut merupakan aturan adat yang terdapat di dalam etnik Rejang, menyebutkan hal tersebut di dalam sambei menandakan bahwa benda maupun kata tersebut secara adat haruslah berpasangan dengan kata atau benda yang lainnya.

Pada SA-NH ditemukan bait yang menunjukan kalimat-kalimat pelipur lara sebagai berikut,

\section{Menurut kehendak, hati Nyawe ku ilang tak ku seding}

Kalimat di atas bermakna menurut kehendak hati, nyawa ku bilang tak ku sedih. Kalimat tersebut bermakna apabila keinginan hatinya tercapai maka nyawanya hilang ia tak akan sedih. Sambei di atas dapat menggambarkan kondisi keinginan yang luar biasa dalam diri seorang manusia, sehingga nyawa pun dapat ditukarkan sebagai bayarannya. Hal ini juga dapat berarti kepasrahan akan keinginan yang mustahil di dapatkan sehingga hanya nyawa yang mampu menebusnya.

\section{PENUTUP}

Berdasarkan rincian masalah dan hasil pembahasan yang telah dipaparkan tentang sambei dan tari kejai dalam bimbang pernikahan etnik Rejang disimpulkan sebagai berikut, bahwa dengan memaknai sambei harus dengan memahami etnografi masyarakat pemilik sambei terlebih dahulu agar mendapatkan makna yang tepat. Berbagai macam sambei yang ditemukan oleh peneliti hampir memiliki beberapa kata yang sama atau bahkan baris kalimat yang mirip, akan tetapi karena perbedaan konteks dan situasi sehingga makna yang terkandung juga berbeda.

Sambei andak pada umumnya berisi ungkapan hati bagi pelantunnya, mereka menggunakan kalimat-kalimat yang bermetafora sehingga sulit untuk memaknainya tanpa memiliki pengetahuan etnografi etnik Rejang. Seperti menganalogikan bujang Rejang yang gagah dan pemberani dengan tokoh sakti yang disegani dalam etnik Rejang salah satunya adalah Ki Rio Setanggai Panjang dan Monok Micor. Sayangnya sangat jarang masyarakat yang mampu memahami makna sambei karena beberapa sambei menggunakan bahasa Rejang yang sangat kuno dan metafora yang sulit dipahami. Lirik dalam sambei juga menunjukkan adanya keberadaan hierarki sosial, adab kesantunan, penunjuk kekuasaan, aturan-aturan adat, nasihat, dan ungkapan pelipur lara.

Terdapat beberapa fungsi dalam sambei, antara lain fungsi pendidikan, fungsi proyeksi dan angan-angan, fungsi penegas pranata sosial, dan fungsi pengesahan lembaga kebudayaan. Sedangkan fungsi pertunjukan adalah sebagai pemanggil roh gaib, peringatan pada nenek moyang, pelengkap ritual tertentu, dan pengungkap keindahan. Hingga saat ini orang 
Rejang masih mengamalkan nilai-nilai yang terkandung di dalam sambei baik secara tersirat maupun tersurat. Hal ini dapat terlihat dengan masih rutin diadakannya perayaan kejai setiap tahun di Kabupaten Rejang Lebong beserta lomba nyambei yang diikuti oleh berbagai kalangan.

\section{DAFTAR RUJUKAN}

Danandjaja, James. 1994. Folklor Indonesia: Ilmu Gosip, Dongeng, dan lain-lain. Jakarta: Pustaka Utama Grafiti.

Kadirman, 2004. Ireak Ca’o Kutei Jang. Jakarta: Balai Pustaka.

Koentjaraningrat, 1974. Kebudayaan Mentalitas dan Pembangunan. Jakarta: PT Gramedia.

Marsden, William. 1996. History of Sumatera. Kuala Lumpur: Oxford University Press.

Reid, Anthony. 2014. Asia Tenggara dalam Kurun Niaga 1450-1680. Jakarta: Yayasan Pustaka Obor Indonesia.

Sedyawati, Edi. 1981. Pertumbuhan Seni Pertunjukan. Jakarta: Sinar Harapan.

Siddik, Abdullah. 1980.HukumAdat Rejang. Jakarta: Balai Pustaka.

Spradley, James. 1997. Metode Etnografi. Yogyakarta: Tiara Wacana. 